Change agency in occupational context: Lessons for HRM*

* The research reported here was funded by the UK Economic and Social Research Council (ESRC - RES 00022 1980A).

\author{
Nick Wylie \\ Oxford Brookes Business School \\ Oxford Brookes University \\ Oxford, OX33 1HX, UK \\ Email: nwylie@brookes.ac.uk \\ (corresponding author) \\ Andrew Sturdy \\ Department of Management \\ University of Bristol \\ Bristol, BS8 1TN, UK \\ Email: Andrew.Sturdy@bristol.ac.uk
}

Christopher Wright

Discipline of Work \& Organisational Studies

University of Sydney

NSW, 2006, Australia

Email: Christopher.Wright@sydney.edu.au 


\title{
Change agency in occupational context: Lessons for HRM
}

\begin{abstract}
Change agency is seen as a key route to reducing the occupational vulnerability of human resource management (HRM). However, few look outside of the HRM context to consider change agency more broadly in organisations. Drawing on a study of change agency units in British organisations, we argue that challenges to occupational credibility and competing jurisdictional claims have wider implications for the role of HR practitioners. In particular, change agency is better seen as replaying rather than resolving the ambiguity of HRM's role and identity in organisations.
\end{abstract}

Key words: change agency, HRM, occupations, jurisdiction, corporate professions, credibility, internal consulting.

\section{Introduction}

Studies of the human resource (HR) function have stressed the need to overcome occupational insecurity by establishing a strategically significant role within organisations. A central theme here has been the development of a more explicit role for the HR function as a 'change agent' (Storey, 1992; Ulrich, 1997). Change agency has long had a place within HRM and personnel management (Legge, 1978), and there is evidence that it has become an increasingly important part of the practice and occupational identity of HRM (Buyens and De Vos, 2001; Caldwell, 2001). Empirical research into HR change agency typically focuses on different role types based on varying change contexts (Alfes, et al., 2010). While there is some recognition of the complexity of HR change agency roles when performed alongside traditional HRM activities (Caldwell, 2001), the extent to which these new roles can be understood in terms of broader issues facing change agency itself is largely neglected. Moreover, there is little attempt to draw on the experiences of change agents more widely to 
understand how they seek credibility in their work roles. This would appear to be very relevant for those HR managers who view change agency as a key route for increased occupational status.

This article seeks to address these issues through a study of change agents operating within specialist change management/internal consulting units in British organisations. Drawing on developments in the sociology of professions, such as the focus on corporate professionalization (Muzio, et al., 2011), we explore two characteristics of these units which are essential to their functioning. First, we suggest that change agents operate within a congested domain in which different managerial occupations claim jurisdiction. Second, such claims require both units and individual change agents to demonstrate credibility through developing relationships, clearly articulating their expertise and establishing positive perceptions of their ability to 'add-value' to the organisation. Paradoxically, these very characteristics have been identified as important for the HR profession as a whole (e.g. Armstrong, 1989) and yet have rarely been explored empirically. Our finding of significant challenges to the credibility of change agents in general, suggests that the notion of $H R$ change agency needs to be developed further, in a broader occupational context.

The article is organised as follows. First, we consider how change agency has become a feature of attempts to resolve the concerns of the HR function and we draw parallels with the study of change agency outside the HR domain. We then show how theories of professionalization and the concept of credibility are relevant to a discussion of change agency. After outlining our empirical study, we examine these issues through an analysis of change agency units. Finally, we consider the broader implications of our findings for HR change agency and the HR function.

\section{HRM and change agency in occupational contexts}

\section{The HR function}


An established theme within literature on the HR function (and personnel management before it) is its precarious position - a poor cousin among management occupations (Bresnen and Fowler, 1996). This has fuelled a preoccupation with enhancing the function's professional status, with HR managers seeking to resolve the problems of role ambiguity and low credibility. Legge $(1978 ; 1995)$ for example, argued that personnel managers historically lacked credibility because their role was ambiguous in terms of comprising both a generic and specialist activity, having uncertain outcomes, and representing both managerial and employee interests.

A number of mechanisms for resolving these issues have been proposed, suggesting a reevaluation of the core values, roles and responsibilities of the HR function. Options range from focusing on boardroom representation (Guest and King, 2004; Caldwell, 2011); outsourcing routine roles (Cooke, et al., 2005); (re) establishing the function's social legitimacy (Kochan, 2007); and building reputational and structural forms of social capital (Truss and Gill, 2009). Arguably the most influential re-evaluation has been the 'Ulrich' model for re-structuring the HR function (Ulrich and Brockbank, 2005). Ulrich (1997) has proposed a number of means through which strategic influence (and therefore occupational status) can be enhanced, such as embedding HR within business divisions (e.g. business partnering), adopting a 'shared-services' model (e.g. HR service centres and Centres of Excellence) and, our particular focus, pursuing a change agency role.

There remains debate about the extent to which the HR function has resolved ambiguities through such re-evaluation. For example, some studies suggest that the adoption of HR change agency roles and the Ulrich model remains limited (Guest and King, 2004; CIPD, 2007; Younger, et al., 2011). And yet it also seems clear that the goal of strategic influence has substantially altered the way in which the HR function understands its core values (Caldwell, 2003a; Roche and Teague, 2012). For example, Francis and Keegan (2006) show how the language of strategic partnership has begun to marginalise the traditional welfare or employee-oriented focus of the HR function (see also Peterson, 2004). Nevertheless, 
continuing uncertainty about the knowledge base of HRM (Thompson, 2011), and its ability to add-value persists (e.g. Guest, 2011). Indeed, such uncertainty may even have become an accepted part of the HR identity (Roche and Teague, 2012).

For some, these concerns fuel a longstanding view of change agency as the solution to the HR function's role ambiguity and low credibility. As Caldwell (2001: 50) argues:

Change agent roles certainly offer the prospect of a way out of the traditional debate on marginalisation versus the overblown ambitions of a profession constantly seeking to secure its professional status and legitimacy

Likewise, both Storey (1992) and Ulrich (1997) regard an association with change as integral to the professional status of the HR function. For example, Storey (1992: 180) has claimed that a 'changemaker' role is 'the natural location of the human resource manager proper', whereas Ulrich's (1997:152) original formulation of the HR function suggested that change agents should have wide-ranging scope to create change programmes which "permeate the soul and mind of the organization'. As a consequence, the ability to manage change is seen as a core competency of the HR practitioner (Becker, et al., 2001), and important in how others view the function more generally (Buyens and De Vos, 2001).

However, despite its centrality within the wider re-evaluation of HR roles, the potential of HR change agency has been questioned. In particular, Caldwell (2001), who outlined a typology of possible HR change roles, suggests that it may exacerbate role ambiguity. A critical concern here is whether the HR change agent performs an explicitly strategic role. For example, the roles of 'change champions' and 'synergists' were seen as primarily concerned with transformational changes, coordinating change programmes for example, and so likely to engage with broader strategic objectives. By contrast, change 'adapters' focused on more incremental change, sometimes operating as specialist 'consultants'. Ambiguity was compounded by the fact that some roles were short lived and overlapping. More recently, Alfes et al. (2010) have pointed to how change agency on its own might not bring enhanced 
status to HR practitioners. Rather, they must be proactive in their approach to their organisations' change initiatives.

\section{Change agency}

One route to better understanding the challenges facing the HR change agent is to consider how change agency operates beyond the HR domain. This is important because there would appear to be significant parallels between the uncertainty and ambiguity associated with the HR function and views of change agency as both a specialist role and a generic managerial skill. The early use of the term 'change agency' can be traced back to the work of Lewin (1951) and the emergence of Organisational Development (OD). Here, focus centred on activities undertaken by (often external) specialists to support processes of planned change. The concern in the literature was to model the various forms or styles of change agency against particular contexts (e.g. Ottaway, 1983). More recently, process traditions of change agency through facilitation (Schein, 1969), have arguably been marginalised in favour of more formalised or product-based interventions (Clegg, et al., 2007). Nevertheless, change agency as a specialist activity can still be seen in the idea of the boundary-spanner (Balogun, et al., 2005), the institutional entrepreneur (Maguire, et al., 2004), and, in particular, the management consultant (Wright, 2009).

Paradoxically, at the same time as these roles have received greater attention, change agency is also assumed to have a broader application. Ottoway (1983: 379), for example, points out that 'everyone is a change agent', and that involvement in change processes is a 'normal part of everyone's life'. Here change agency becomes a generic management activity and skill required in the modern-day workplace, dispersed beyond dedicated individuals or units (Buchanan, et al., 2007). This can blur distinctions between the change 'drivers' and 'driven' (Buchanan, et al., 2007), and create difficulties in identifying change agent competencies and skills (Doyle, 2002). Similar to the HR function then, this view of 
change agency can lead to ambiguity in distinguishing its core activities from those of line or middle management. Indeed, Caldwell (2003b: 140) argues that a 'management model' of change agency includes 'middle-level managers and functional specialists who adapt, carry forward or build support for strategic change within business units or key functions'.

This extended view of change agency as a generalist activity in part explains why occupational groups other than HR have sought to appropriate it as a way of establishing their organizational contribution. For example, OD specialists still claim expertise in change agency (e.g. Hornstein, 2001), and 'change management' is a core element of external and internal management consultancy more generally (Werr, et al., 1997). At the same time, both project and interim management also claim expertise in managing change, especially regarding specific projects and programmes (Association of Project Management, 2012). As we discuss below, the credibility of change agents is critical to establishing a role within this congested environment, something that once again indicates parallels with the HR function's on-going effort to establish its own credentials in relation to other managerial groups. However, there has been little attempt either in studies of change agency, or its HR variant, to consider issues of professional jurisdiction or credibility and their effect on how change agency operates within organisations.

The neglect in the literature on HR change agency is perhaps unsurprising as attention tends to be given to how change agency resolves the problems of the HR function overall (Alfes, et al., 2010; Caldwell, 2001). Also, ambiguity in HR change agency tends to be related to confusion within or between different change agency roles. This has led to an inward-looking debate in which the problems of the HR function are considered in isolation, rather than as part of a wider set of challenges implicit within asserting occupational identity and jurisdiction. For example, how do professionalizing occupations in general seek to acquire responsibilities which improve their material and symbolic position (e.g. the shift of accounting into management consultancy) (McDougald and Greenwood, 2012)? We argue that there are significant lessons to be learned for an understanding of HR change agency 
from examining the parallel concerns of change agency more generally and by drawing on theories of occupations and credibility. Before turning to our data we examine professional jurisdiction and sources of credibility in more detail.

\section{Professional jurisdiction}

The adoption or appropriation of change agency roles within HRM can be seen as jurisdictional claims. Following Abbott (1988), rather than viewing occupations in isolation, we need to consider the more or less explicit competition between them. In particular, securing and defending control over certain activities is seen as central to maintaining and developing occupational status, and sustaining a broader 'professional project'. In some contexts, 'jurisdictional boundaries are perpetually in dispute' (ibid: 2) such that any attempt to acquire new responsibilities must be done with an understanding of the competing claims of other professions. Although not all claims are explicitly contested, what can emerge in this process is the ranking of different occupations and defensive antagonism between them (Armstrong, 1989).

Arguably, the challenge of asserting jurisdiction for the HR function has increased in recent years with the development of rival 'knowledge-based' occupational groups or 'corporate professions' such as management consultancy or project management (Muzio, et al., 2011; Reed, 1996). These groups have actively sought a professional status, but have rejected some of the traditional methods of achieving this, such as establishing a single entry point into the profession. Moreover, these groups have sought to establish jurisdiction by accommodating organisational/business imperatives (e.g. efficiency and value creation) within their own knowledge base. In so doing, they have created a congested and ambiguous context of professional influence within organisations. For example, concerns over HRM's response to inter-professional competition have been explored in the context of accounting (Armstrong, 1989) and, more recently, management, in the form of consultancy 
and its change agency role. Here, Wright (2008) has argued that the HR 'business partner' position has come under increasing pressure from the recruitment of former external management consultants into organisations who claim both people and change management expertise yet explicitly reject any association with the HR profession. Outside of these examples a more comparative analysis of the HR professionalization agenda remains rare and discussions of HR change agency roles are not explicitly located within a context of competing jurisdictional concerns (Alfes, et al., 2010; Caldwell, 2001; Storey, 1992; Ulrich, 1997).

As we have seen, this is also important because the wider change agency literature suggests that it too faces challenges to its occupational status from management consultants, project managers and OD specialists (e.g. Hornstein, 2001). Consequently, our analysis emphasises the congested domain within which change agents operate and explores the methods through which they seek professional jurisdiction. Fundamental to this process is the concept of credibility to which we now turn.

\section{Credibility}

Successful claims to jurisdiction over change agency rely upon occupational groups such as HR or OD specialists having both legitimacy and credibility. Legitimacy refers to 'a generalized perception or assumption that the actions of an entity are desirable, proper or appropriate' (Suchman, 1995: 574). It is therefore associated with, but not entirely dependent upon the behaviour of those entities; meaning legitimacy can be retained even in the face of inappropriate behaviour. For example, despite public animosity towards banks' activities, banks remain legitimate providers of financial services. By contrast, credibility relates more to the degree of trust placed in actors to solve problems or address the concerns of senior management or other 'clients' (Denis, et al., 2007; Armstrong, 1989). As Sobel (1985: 557) argues, 'someone becomes credible by consistently providing accurate 
and valuable information or by performing useful services'. Consequently, it is possible for an individual or occupational group to be considered legitimate (i.e. to assert a jurisdictional claim over a certain practice), but to lack credibility (i.e. to not be trusted to appropriately exercise that claim). However, credibility in any meaningful sense cannot exist without legitimacy, meaning it is unlikely trust will be placed in those who have no legitimate claim to insight in a specific domain. For example, HR professionals might have some legitimate jurisdictional claim over recruitment and selection activities, but they will only acquire credibility if line managers trust them to attract and appoint candidates effectively. This suggests that credibility is a more informal, fluid and localised concept, with actors drawing on broader forms of legitimation (e.g. social norms, values) in their particular contexts.

In order to examine the role of credibility in relation to change agency we identified three distinct, but closely related sources: relationships, expertise and 'added-value'. As we shall see below, these emerged from our data analysis, but are supported more widely in related literature. In particular, relationships or associations - 'who you know' - as a source of credibility are often linked to status, social capital or 'networked reputation' (Glückler and Armbrüster, 2003; Truss and Gill, 2009). For example, in the boundary spanning activity of management consultancy, the status of previous clients (and of employers), and the quality or longevity of client relations can be important to credibility with client managers (Sturdy and Wright, 2011). Likewise, in the context of HR specialists, Truss and Gill (2009) show how others' perceptions are crucially dependent upon both structural characteristics (e.g. their position within a wider network) and relational issues (e.g. trust, mutual obligations).

An important dimension of these relationships and a second source of credibility is an occupation's specific claim to expertise. Here, various cognitive, technological and political resources are deployed rhetorically towards senior management (Reed, 1996; Armstrong, 1989; Covaleski, et al., 2003). As we have seen, in the case of change agency, developing such credibility has been problematic due to tensions or ambiguities between inclusive, 'process consulting' traditions (Ottaway, 1983), increasingly popular product-based 
interventions (Caldwell, 2005), and the view of change agency as a generic and largely accessible management skill (Caldwell, 2003b).

While traditionally the value of many professions was claimed through appeals to altruism and contributing to the public good (Abbott, 1988), within the managerial or corporate professions, the more common source of credibility is based more on the efficiency of the service it provides and its identifiable impact. Being seen to 'add value' is of particular importance for these groups as their expertise is often limited to perhaps one organisation or industry and is assessed on the basis of its commercial application (Muzio, et al., 2011).

Overall then, we propose an alternative framework through which to explore change agency that comprises competition over professional jurisdiction, and the securing of individual and occupational credibility through relationships, expertise and added-value.

\section{Research methods and context}

The data drawn upon here is part of a broader project on the role of change agency units (Authors, 2012). We define change agents as specialist staff who provided change advice, facilitation and management, typically on a project/programme basis. As a result, our participants included both those who were exclusively change agents and those embedded in specialist functions. This definition allowed us to explore how change agency (sometimes labelled 'internal consultancy') might act as a mechanism for organizing 'service' functions such as HR, but also others such as audit and IT .

Most research into change agency and internal consultancy focuses on the individual change agent (Neal and Lloyd, 1998) and so less is known about how it is organised, its wider occupational context and the challenges faced by units in securing an impact. Consequently, our approach was primarily exploratory with these issues informing the initial objectives of the broader research project. In the absence of a formal database of change 
agency units, we adopted a 'convenience sampling' approach in which respondents were identified via information drawn from relevant professional publications (e.g. job advertisements in management magazines) and associations (e.g. The Institute of Consulting). Drawing on our definition of change agents, we used these sources progressively to identify 24 organisations which contained units, departments or groups which had a specific change, consultancy or business improvement focus and to which we could gain access. To our knowledge, this represents one of the largest ever studies of change management units, comprising considerable contextual variety (see Table 1). This, combined with more extensive research access in three cases, meant that, overall, we were able to identify some common features of change agency and draw lessons for other professional groups such as HR.

Given the exploratory nature of our research, we did not seek to produce generalisable claims nor make systematic comparisons, between sectors for example. Our primary focus was on shared experiences. Furthermore, we cannot claim that our sample is representative of change agency units generally. Due to the ambiguous occupational boundaries and lack of clear institutionalisation in change agency, the population of units is necessarily uncertain. Moreover, in terms of sectors, our sample has a particular profile. The public sector (e.g. government departments and health care) and financial services are over-represented, while manufacturing is absent.

Overall, semi-structured interviews, lasting between 1-2 hours, with 93 individuals were conducted. Units varied in size from those comprising only two or three change agents to over fifty, based within internal hierarchies. For the most part, we sought to address research themes via an interview with the unit manager. In a number of organisations, interviews were also conducted with other change agents and in three cases, we were also able to interview some of their clients (see also Table 1). Interviews were recorded and transcribed and we used an iterative process of data analysis which involved the detailed interrogation and coding of interview transcripts based on the central research themes outlined above. In 
particular, this framework evaluated each change unit in terms of its current form and structure; methods and work practices and perceived impact, plus any changes and challenges the unit had experienced in these areas.

It was clear from this initial analysis that there was some variation between units and that there was no standard narrative as to how the role of change agency had developed. However, a central theme was the dynamic and fragile nature of change agency, based upon its open/discretionary and congested nature. Indeed, 4 of the 24 units were disbanded during the period of the research. This presented a challenge for change agents in establishing a coherent role for themselves and communicating this to others. In the following sections, we outline in more detail the four key themes to emerge from the analysis - occupational congestion and credibility through relationships, expertise, and added-value before returning to specific implications for the HR function in the discussion and conclusion. Table 1 summarises the results of this analysis across our sample, specifically in relation to (a) each unit's sources of credibility and (b) the existence of alternative and/or competing forms of change agency in the organisation.

INSERT TABLE 1 ABOUT HERE

\section{The challenges of change agency}

\section{A congested domain}

The notion of change agency as subject to different jurisdictional claims was evident in our study through the varied occupational backgrounds of individuals operating within change management units. The most common functional area was operations management, focusing on efficiency gains and various 'lean' methodologies such as 'Six Sigma'. Here, many change agents came from engineering backgrounds and saw their role as achieving process or systems change. Others were psychologists, often identifying with the field of OD, 
engaging in conflict resolution or functional integration. Project or programme management expertise was also represented, offered as a service on change projects. Finally, some change agents had a background in external management consultancy and, in a limited number of cases, supported strategic decision making.

For the most part, the change service offered by units was discretionary for 'clients'. Except in the case of some large scale change programmes, line managers were not obliged to go to the change units. Indeed, in many cases, managers could not only act as change agents themselves or seek external consultancy support, but had alternative independent providers internally, including HRM departments. For example, in FinCo1, a global financial services organisation, there were seven other internal consultancy groups, in addition to numerous 're-engineering', project management, quality and strategic planning groups embedded in individual business units. Change agency could therefore be a highly congested domain. Whilst this competition could be managed to help ensure that these units did not, as a change agent in GovServ2 commented, 'eat each other's sandwiches', in some instances there was considerable overlap and occasional conflict.

To add to the complexity, there was variation in terms of where change agency units were structurally located (see Table 1). A small number were independent and reported directly to the Chief Executive Officer (CEO), whereas most were located within service functions, including HR. Interestingly, some change management units could be located within HR functions even if they were made up of entirely non-HR staff (operations management and logistics in one instance). In such cases, HR had successfully managed to capture change agency as a functional responsibility, but not as an occupational domain. More generally however, the openness of change agency as an activity meant that change units (within HR or not) were contrasted with HR departments as a whole. The latter typically were nearmonopoly providers to line managers which generated ongoing or permanent service relationships not evident in the change domain. It is this discretionary (and open) feature of 
the change units' service in particular, which intensified the ongoing concern to establish their credibility.

\section{Credibility through relationships}

As we have seen, being trusted to resolve the concerns of others through relationships, expertise and added-value, is clearly important in a range of occupational fields. For a substantial number of units, relationship-based credibility was seen as crucial, not simply for success, but in securing the basic resources required to operate. Such concerns were well founded given the number of units which were disbanded, shifted location or reduced in size and scope. More generally, change agents saw formal and informal relationships with senior management as critical to their credibility. In HealthCo2 for example, the CEO was, according to the change agency manager, 'utterly convinced' of the value of retaining specialist change agents. As a consequence, this unit was considered to have high credibility in the organization and was able to highlight this when encouraging different functional areas to use their services.

Senior management support however, could be a double edged sword in that hierarchical power could serve to undermine, as well as enhance, credibility. Change agents recognized this in the risks attached to having their credibility tied too closely to one or two senior individuals. In LocalGov1 for example, an internal consultancy manager saw that their links with the CEO meant that 'some people are suspicious of us' and that it 'closes some doors because we're close to him'. Similarly, in FinCo4, an internal consultancy unit had reported to the Deputy CEO for a number of years. According to the unit manager, when this individual retired, the new Deputy CEO, 'took one look at it and said..."I don't want an internal consultancy anymore"'. Unsurprisingly the unit was quickly disbanded.

Some change agency units actively sought to establish a wider network of relationships. This could mean expanding their internal client base by better communicating their role (e.g. via 
newsletters or intranet sites) or consciously building relationships with specific divisions. In the case of HealthCo1, the change agency group built relationships by training departmental managers and employees in a distinctive change methodology on the assumption that these individuals would act as advocates. In some cases, units extended their credibility by acquiring external clients. In HealthCo2 for example, the unit manager claimed that, 'we've always maintained a small external client group as well because part of the reason we've got so much credibility is that we're not only internally focused'.

However, diversification of relationships in this way also carried risks by extending change agents' roles beyond their available resources. As the manager of the change agency unit in GovServ3 stated, 'the danger then is of course you get floods of requests for work which you can't do'. Nevertheless, developing wider connections was, for the most part, seen as valuable in sustaining the change agents' credibility. It was also useful in terms of providing the necessary interaction to generate new business and span knowledge boundaries, which, as we shall see below also helped improve credibility.

\section{Credibility through expertise}

Credibility was strongly linked to perceived expertise in different domains - the organization, its sector and/or change management skills. While such expertise could be reflected in the perceived quality of the work delivered, in the congested domain of change agency, the expertise of individuals and units was often a relative phenomenon. For example, units could be bypassed in favour of external or internal alternatives. One change agent in GovServ3 reflected on this issue:

I tell the anecdote of my own boss who said, "Oh (Manager X) wants this piece of work doing. It's certainly not a McKinsey's job, we might call on the externals on our (preferred supplier) framework, the second league ... or we could even let the internals have a go at it." 
Credibility derived from expertise could also be affected by the occupational background of change agents. In units which adopted an explicit identity as an internal consultancy for example, this meant overcoming sometimes negative client perceptions of consultancy more generally. Likewise, one change agent who operated from the HR function in ArtsCo explained that:

The fact that I'm from HR is sometimes the thing I have to get over [conceal] more than anything else, so I kind of don't tell people. I say "I'm from an innovation background and I help people change".

This indicates the extent to which HR change agents may be undermined by pre-existing perceptions of HR regardless of their specific expertise. One method of overcoming this was to associate with specific areas of expertise or change methodologies and claim jurisdiction over large-scale change programmes. However, in such cases, change agents became especially vulnerable to the fashion-like nature of some management knowledge. For example, in CommsCo, a number of change agents were specialists in the branded methodology, 'Six Sigma'. This lost its prestige in the company, resulting in change agents concealing its continued use by dropping the label to outsiders and naming themselves 'the secret Six Sigma society'. However, specializing in large scale change programmes carried less risk in the short term, as it often came with initial senior management support.

The perceived expertise of the individual change agent, as opposed to the units' collective expertise, was also important in terms of establishing credibility for the unit as a whole. Change agency managers often emphasized the distinctive capability of particular change agents compared to that of operational managers. This extended beyond strict domains of expertise towards orientations and aspirations. In Govserv2 for example, the unit manager argued that the credibility of his team had improved by replacing the image of 'old and bold individuals' with one of ambitious staff with change management qualifications. On the other 
hand, in GovAgency1, the unit manager bemoaned the lack of credibility of his change agents, claiming that the unit would be more credible:

If I had a team of people that the business [clients] would say, "I want them working for me, because they're part of this internal consultancy team. Get them in here (be)cause these guys are sharp." We haven't got that image and I don't think we'll get that image.

Consequently, expert status was fragile and change agents were vulnerable to the influence of wider, changing images of particular management functions, specialisms and methodologies.

\section{Credibility through 'adding value'}

Over and beyond their standing as experts, change agents needed to convince others that their work had a 'bottom line' impact if they were to maintain their organisational credibility. Once again, this is an issue familiar in a HR context where concerns around performance impact have been a recurring theme within the search of occupational status. For change unit managers, such as in HealthCo2, the manner in which 'added-value' could be measured and communicated was often a preoccupation:

It's very, very important that the business [internal clients] perceives us as value adding, and that's something we work really, really hard at, to make sure that the business constantly thinks "yeah, these are good guys to have around".

In LocalGov2, demonstrating the value created through reducing costs was integral to the ongoing existence of the change unit - 'If we don't deliver on the targets that we're set, then the team has no future'. However, in other contexts, and with a clear echo of HR practitioners, strategic work was seen as not only more attractive, high status, and directly associated with 'added-value', but also crucial for continued existence. In GovDept1, the change unit was disbanded because it had undertaken: 
...probably too much of the tactical level stuff. Going out and just re-validating how many posts you should have in a particular area to do a certain amount of work, which in retrospect I don't think was the best use of their time.

Change agency units relied mostly on client perceptions of their added-value, typically measured through post-intervention feedback and by demonstrating performance against agreed objectives (see also MCA, 2010). However, perceptions of added-value varied with changes in the demand for change agency services and intensified pressure to deliver in increasingly tough financial times. This contributed to some units looking to diversify their profile into more 'value-adding' activities. The change unit in HealthCo1 for example, highlighted how it had diversified into project management:

We've evolved from being a team that's concentrating on forming and making teams within the organisation, to more the role which is helping the whole organisation with its projects.

Although the need to demonstrate added-value was part of the attraction of change agency, the broader lack of recognition of its potential was also a source of frustration. As one manager in a central government service commented:

My annual report explained....the sorts of benefits I thought we delivered. And [I argued] that I should be used to help deliver the board's management plan....And they debated this for twenty minutes came back with the answer, "no, you please crack on and do what you keep doing."

Such an account resonated with the frustrations of many change agents in that other groups, especially external consultants, continued to be seen as more credible actors in the change agency space.

\section{Discussion}


Our examination of change agency units in different organisational settings highlights the challenges of establishing credibility among sponsors and clients. In line with theories of how managerial occupations seek status as corporate professions, we have shown how competing jurisdictional claims, and three sources of credibility - relationships, expertise and added-value - are central to the development of change agency as a separate management function within organisations (see summary in Table 2).

INSERT TABLE 2 ABOUT HERE

This analysis has a number of implications for understanding HR change agency. Existing literature has tended to identify typologies of HR change agency, or argued how it fits within a wider re-design of HR (Alfes, et al., 2010; Caldwell, 2001; Storey, 1992; Ulrich, 1997). Our analysis adds to this literature by placing HR change agency in a broader occupational context and suggesting caution in assuming a change role will inherently improve HR impact and status. Whilst neglect of the wider change management context in HR research is understandable, it does lead to change agency being assessed only in relation to the occupational insecurities of HR practitioners. In fact, we have seen how insecurity can also be seen as a characteristic of change agency in general.

By bringing the experience of non-HR change agents into the debate and drawing attention to occupational jurisdiction and congestion, our analysis shows what lies behind Caldwell's (2003a) suggestion that the ability of change agency to solve the ambiguity of the HR function is impeded. In particular, we show how the problem of credibility is central to these ambiguities and to effecting change agency more generally. Again this is something which is not sufficiently explored in the literature, not least because it is not immediately obvious how HR change agency can develop credibility in a way which allows it to assert a jurisdictional claim over and above competing groups. For example, in terms of relationships, our analysis shows that change agents are reliant upon hierarchical sponsorship, but will also seek to extend their network more broadly in order to mitigate the risks involved in being too closely 
aligned with senior individuals. For the HR change agent, such relationships may be embedded within functional reporting lines and so the scope for expanding networks may be more limited. Moreover, if involvement in change projects is considered a new development for HR managers, then reliance on senior sponsors is likely to be of greater importance in order to build credibility or acceptance across the organisation. However, as the debate about the HR function's representation amongst senior management continues (Caldwell, 2011; Guest and King, 2004), it may be that the conditions for a successful jurisdictional claim and enhanced credibility through senior sponsorship cannot be assured. Here, more needs to be understood about the nature of the HR function's credibility in specific contexts before claims about the positive effect of HR change agency can be made.

Our study also reinforces the view that claims to expertise are integral to establishing credibility. We found change agents keen to assert their unique or specialist knowledge within their organisations as well as the value-adding nature of their role, both of which could be extended by diversifying their product offering. However, within the HR change agency literature, little attention is focused on what might be the unique claims of expertise that HR practitioners possess in the area of change agency. There is some examination of how HR is well placed to deliver changes to people management practices (Thornhill, et al., 2000) and provide administrative or organisational skills to change projects (Caldwell, 2001), but little on how the HR knowledge base offers distinctive skills in relation to other change agents. If anything, HR may be at a disadvantage. For example, as Caldwell (2003b) argues, and as evidenced by the backgrounds of many change agents in our study, change management has become increasingly reliant on process-based methodologies (e.g. PRINCE 2). This suggests that other occupations such as project management have already successfully asserted some jurisdictional claims in the area. Another option may be for HR change agents to legitimise projects through focussing on the 'people management' aspects of change. However, this is seen by some as the legitimate domain of change agents who explicitly denied an association with the HR function. Once again, we see that any attempt to 
move into areas beyond what might be considered the standard HR responsibilities is likely to be challenged and may not be achieved simply through broad assertions of the need for HR practitioners to become more change or business-oriented (Ulrich 1997; Ulrich and Brockbank, 2005).

\section{Conclusion}

The prospects for HR change agency crucially depend upon the ability to demonstrate a distinctive and valued contribution. More specifically, this contribution would be one that is not easily replicated, could add-value over and above more established or specialist changeoriented occupational groups, and which acknowledged the likely effect of pre-existing perceptions of the HR function. This would involve an assessment of how relationships, expertise and added-value as potential sources of credibility might combine to support HR change agency and enable it to act as a mechanism in moving away from traditional HR responsibilities. Even with this understanding, the experience of change agents in this study suggest that such a shift may still not overcome the fundamental ambiguity of the HR function.

Indeed, we have seen how change agency itself represents a challenging domain in which to operate for some of the very reasons which underlie the insecurities of the HR function. Paradoxically then, there is a danger that shifting towards change agency may simply replay rather than resolve issues of occupational credibility and insecurity facing HRM. Our study therefore supports and extends Caldwell's (2003a) suggestion that change agency can cause further role ambiguity. However, this assumes that resolving ambiguity remains a key concern. Indeed, for the change agents studied here, although a lack of credibility could be frustrating, the ambiguous and unpredictable nature of their role was sometimes valued. Likewise, as Roche and Teague (2012) suggest in the context of HR practitioners, there is greater acceptance of ambiguity and the ability to play multiple roles. Here, HR managers 
take a more pragmatic approach to sustaining whatever influence they have. This suggests the need for a change in focus in any appraisal of the HR function's search for increased occupational security, one which allows for a greater tolerance of ambiguity.

More generally, our study also suggests avenues for further research. For instance, there is a need for systematic comparisons between contexts, where one might directly compare change units located within and beyond HR functions and assess change agency in (organisational and sectoral) contexts where HR has varying levels of status. Likewise, research might compare competing change units in the same organisation or change agency in relation to other occupations such as project management, IT and audit for example. Finally, future research might examine the role of change agency in more established fields of HR activity (e.g. recruitment and rewards) through HR Centres of Excellence for example. Here, expertise, added-value and diversified relationships might be more clearly articulated and there are less likely to be competing or alternative providers. Here, different forms of credibility will, no doubt, remain crucial. 


\section{References}

Abbott, A., (1988). The System of Professions: An Essay on the Division of Expert Labor, Chicago: University of Chicago Press.

Alfes, K., Truss, C. and Gill, J., (2010). 'The HR Manager as Change Agent: Evidence from the Public Sector'. Journal of Change Management, 10 (1):109-127.

Armstrong, P., (1989). 'Human resource management in an age of management accountancy'. In: Storey, J. (ed). New Perspectives on Human Resource Management. London: Routledge, 154-166.

Association of Project Management, (2012). APM Body of Knowledge. 6th edn, London: APM.

Balogun, J., Gleadle, P., Hope-Hailey, V. and Willmott, H., (2005). 'Managing Change Across Boundaries: Boundary-Shaking Practices'. British Journal of Management, 16 (4):261-278.

Becker, B.E., Huselid, M.A. and Ulrich, D., (2001). The HR Scorecard: Linking People, Strategy, and Performance, Boston: Harvard Business School Publishing.

Bresnen, M. and Fowler, C., (1996). 'Professionalization and British management practice'. Journal of Management Studies, 33 (2):159-182.

Buchanan, D.A., Addicott, R., Fitzgerald, L., Ferlie, E. and Baeza, J.I., (2007). 'Nobody in charge: Distributed change agency in healthcare'. Human Relations, 60 (7):10651090.

Buyens, D. and De Vos, A., (2001). 'Perceptions of the value of the HR function'. Human Resource Management Journal, 11 (3):70-89.

Caldwell, R., (2001). 'Champions, Adapters, Consultants and Synergists: The New Change Agents in HRM'. Human Resource Management Journal, 11 (3):39-52.

Caldwell, R., (2003a). 'The Changing Roles of Personnel Managers: Old Ambiguities, New Uncertainties'. Journal of Management Studies, 40 (4):983-1004.

Caldwell, R., (2003b). 'Models of Change Agency: A Fourfold Classification'. British Journal of Management, 14 (2):131-143.

Caldwell, R., (2005). 'Things fall apart? Discourses on agency and change in organizations'. Human Relations, 58 (1):83-114.

Caldwell, R., (2011). 'HR directors in UK boardrooms: A search for strategic influence or symbolic capital?'. Employee Relations, 33 (1):40-63.

CIPD, (2007). The Changing HR Function, London: Chartered Institute of Personnel and Development.

Clegg, S.R., Rhodes, C. and Kornberger, M., (2007). 'Desperately Seeking Legitimacy: Organizational Identity and Emerging Industries'. Organization Studies, 28 (4):495513. 
Cooke, F.L., Shen, J. and McBride, A., (2005). 'Outsourcing HR as a competitive strategy? A literature review and an assessment of implications'. Human Resource Management, $44(4): 413-432$.

Covaleski, M., Dirsmith, M.W. and Rittenberg, L., (2003). 'Jurisdictional disputes over professional work: The institutionalization of the global knowledge expert'. Accounting, Organizations and Society, 28 (4):325-355.

Denis, J.-L., Langley, A. and Rouleau, L., (2007). 'Strategizing in pluralistic contexts: Rethinking theoretical frames'. Human Relations, 60 (1):179-215.

Doyle, M., (2002). 'Selecting managers for transformational change'. Human Resource Management Journal, 12 (1):3-16.

Francis, H. and Keegan, A., (2006). 'The Changing Face of HRM: In Search of Balance'. Human Resource Management Journal, 16 (3):231-249.

Glückler, J. and Armbrüster, T., (2003). 'Bridging Uncertainty in Management Consulting: The Mechanisms of Trust and Networked Reputation'. Organization Studies, 24 (2):269-297.

Guest, D., (2011). 'Human resource management and performance: still searching for some answers'. Human Resource Management Journal, 21 (1):3-13.

Guest, D. and King, Z., (2004). 'Power, Innovation and Problem-Solving: The Personnel Managers' Three Steps to Heaven?'. Journal of Management Studies, 41 (3):401423.

Hornstein, H., (2001). 'Organizational Development and Change Management: Don't Throw the Baby out with the Bath Water'. Journal of Applied Behavioral Science, 37 (2):223226.

Kochan, T., (2007). 'Social legitimacy of the human resource management profession: a U.S. perspective'. In: Boxall, P., Purcell, J. and Wright, P. (eds). The Oxford Handbook of Human Resource Management. Oxford: Oxford University Press.

Legge, K., (1978). Power, Innovation, and Problem-Solving in Personnel Management, London: McGraw-Hill Book Company.

Legge, K., (1995). Human Resource Management: Rhetorics and Realities, London: Macmillan.

Lewin, K. (ed), (1951). Field Theory in Social Science. New York: Harper \& Row.

Maguire, S., Hardy, C. and Lawrence, T.B., (2004). 'Institutional entrepreneurship in emerging fields: HIVIAIDS treatment advocacy in Canada'. Academy of Management Journal, 47 (S):657-679.

MCA, (2010). The value of consulting: An analysis of the tangible benefits of using management consultancy, London: MCA.

McDougald, M.S. and Greenwood, R., (2012). 'Cuckoo in the Nest? The Rise of Management Consulting in Large Accounting Firms'. In: Kipping, M. and Clark, T. (eds). The Oxford Handbook of Management Consulting. Oxford: Oxford University Press, 93-116. 
Muzio, D., Hodgson, D., Faulconbridge, J., Beaverstock, J. and Hall, S., (2011). 'Towards corporate professionalization: The case of project management, management consultancy and executive search'. Current Sociology, 59 (4):443-464.

Neal, M. and Lloyd, C., (1998). 'The Role of the Internal Consultant'. In: Sadler, P. (ed). Management Consultancy: A Handbook of Best Practice. London: Kogan Page, 432446.

Ottaway, R.N., (1983). 'The Change Agent: A Taxonomy in Relation to the Change Process'. Human Relations, 36 (4):361-392.

Peterson, R.B., (2004). 'A Call for Testing our Assumptions: Human Resource Management Today'. Journal of Management Inquiry, 13 (3):192-202.

Reed, M., (1996). 'Expert Power and Control in Late Modernity: An Empirical Review and Theoretical Synthesis'. Organization Studies, 17 (4):573-597.

Roche, W.K. and Teague, P., (2012). 'Business partners and working the pumps: Human resource managers in the recession'. Human Relations, 65 (10):1333-1358.

Schein, E., (1969). Process Consultation: Its Role in Organization Development, Reading, Mass.: Addison-Wesley.

Sobel, J., (1985). 'A Theory of Credibility'. The Review of Economic Studies, 52 (4):557-573.

Storey, J., (1992). Developments in the Management of Human Resources: An Analytical Review, Oxford: Blackwell Business.

Sturdy, A. and Wright, C., (2011). 'The active client: The boundary-spanning roles of internal consultants as gatekeepers, brokers and partners of their external counterparts'. Management Learning, 42 (5):485-503.

Suchman, M.C., (1995). 'Managing Legitimacy: Strategic and Institutional Approaches'. Academy of Management Review, 20 (3):571-610.

Thompson, P., (2011). 'The trouble with HRM'. Human Resource Management Journal, 21 (4):355-367.

Thornhill, A., Lewis, P., Millmore, M. and Saunders, M., (2000). Managing Change: A Human Resource Strategy Approach, Harlow: Financial Times Prentice Hall.

Truss, C. and Gill, J., (2009). 'Managing the HR Function: The Role of Social Capital'. Personnel Review, 38 (6):674-695.

Ulrich, D., (1997). Human Resource Champions, Boston: Harvard University Press.

Ulrich, D. and Brockbank, W., (2005). The HR Value Proposition, Harvard, MA: Harvard Business School Publishing.

Werr, A., Stjernberg, T. and Docherty, P., (1997). 'The Functions of Methods of Change in Management Consulting'. Journal of Organizational Change Management, 10 (4):288-307.

Wright, C., (2008). 'Reinventing Human Resource Management: Business Partners, Internal Consultants and the Limits to Professionalisation'. Human Relations, 61 (8):10631086. 
Wright, C., (2009). 'Inside Out? Organizational Membership, Ambiguity and the Ambivalent Identity of the Internal Consultant'. British Journal of Management, 20 (3):309-322.

Younger, J., Younger, A. and Thompson, N., (2011). 'Developing the skills of HR business partnership: consulting and change management'. Strategic HR Review, 10 (1):6-14. 
Table 1 - Summary of sample and data

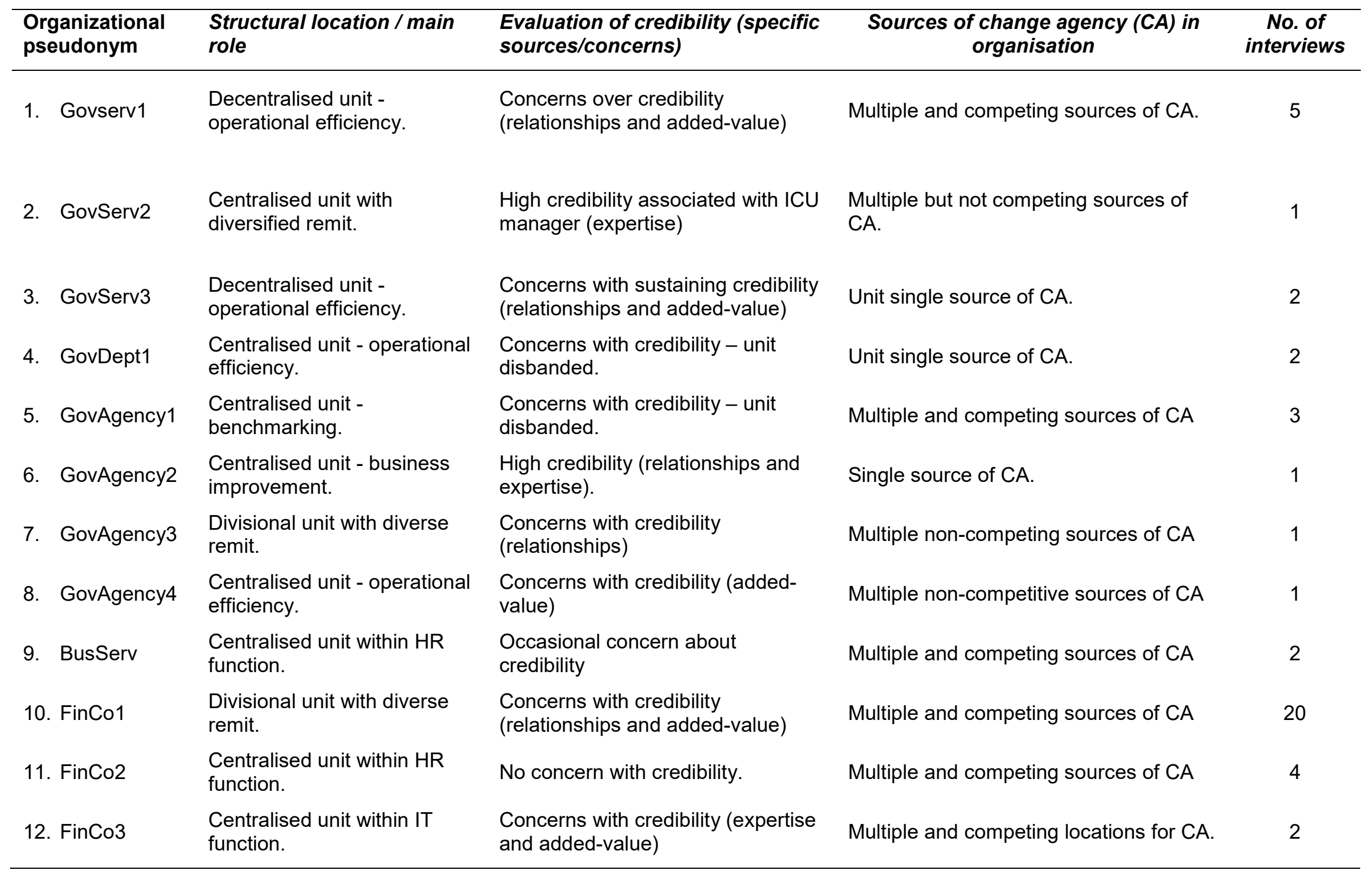




\begin{tabular}{|c|c|c|c|c|}
\hline $\begin{array}{l}\text { Organizational } \\
\text { pseudonym }\end{array}$ & $\begin{array}{l}\text { Structural location / main } \\
\text { role }\end{array}$ & $\begin{array}{l}\text { Evaluation of credibility (specific } \\
\text { sources/concerns) }\end{array}$ & $\begin{array}{c}\text { Sources of change agency }(C A) \text { in } \\
\text { organisation }\end{array}$ & $\begin{array}{c}\text { No. of } \\
\text { interviews }\end{array}$ \\
\hline 13. FinCo4 & $\begin{array}{l}\text { Centralised unit - operational } \\
\text { efficiency. }\end{array}$ & $\begin{array}{l}\text { Occasional concerns with credibility } \\
\text { (relationships) - unit disbanded. }\end{array}$ & Multiple and competing sources of CA. & 1 \\
\hline 14. HealthCo1 & $\begin{array}{l}\text { Centralised unit - OD style } \\
\text { facilitation. }\end{array}$ & No concern with credibility. & $\begin{array}{l}\text { Multiple and non-competing sources of } \\
\text { CA }\end{array}$ & 16 \\
\hline 15. HealthCo2 & $\begin{array}{l}\text { Centralised unit - OD } \\
\text { interventions. }\end{array}$ & $\begin{array}{l}\text { High credibility (relationships, } \\
\text { expertise, added-value) }\end{array}$ & Single source of CA & 1 \\
\hline 16. HealthCo3 & $\begin{array}{l}\text { Centralised unit with diverse } \\
\text { remit.. }\end{array}$ & $\begin{array}{l}\text { Concerns with credibility (added- } \\
\text { value) }\end{array}$ & Single source of CA & 1 \\
\hline 17. HealthCo4 & $\begin{array}{l}\text { Centralised within IT } \\
\text { function. }\end{array}$ & $\begin{array}{l}\text { Concerns with credibility } \\
\text { (relationships, expertise) }\end{array}$ & $\begin{array}{l}\text { Multiple but non-competing sources of } \\
\text { CA. }\end{array}$ & 1 \\
\hline 18. LocalGov1 & $\begin{array}{l}\text { Centralised unit - } \\
\text { performance reporting. }\end{array}$ & $\begin{array}{l}\text { Occasional concern with credibility } \\
\text { (relationships, expertise) }\end{array}$ & Single source of CA & 3 \\
\hline 19. LocalGov2 & $\begin{array}{l}\text { Centralised unit - large-scale } \\
\text { change programme. }\end{array}$ & $\begin{array}{l}\text { No concern with credibility } \\
\text { (relationships, added-value) }\end{array}$ & Single source of CA & 2 \\
\hline 20. LocalGov3 & $\begin{array}{l}\text { Centralised unit - process } \\
\text { improvement. }\end{array}$ & $\begin{array}{l}\text { No concern with credibility } \\
\text { (expertise) }\end{array}$ & Single source of CA & 1 \\
\hline 21. LocalGov4 & $\begin{array}{l}\text { Centralised unit - } \\
\text { performance reporting. }\end{array}$ & $\begin{array}{l}\text { Occasional concern with credibility } \\
\text { (relationships) }\end{array}$ & Multiple and competing sources of CA & 1 \\
\hline 22. ArtsCo & $\begin{array}{l}\text { Centralised within } \mathrm{HR} \\
\text { function. }\end{array}$ & $\begin{array}{l}\text { Occasional concern with credibility } \\
\text { (expertise) }\end{array}$ & $\begin{array}{l}\text { Multiple but non-competing sources of } \\
\text { CA }\end{array}$ & 3 \\
\hline 23. CommsCo & $\begin{array}{l}\text { Divisional unit - large scale } \\
\text { change programme. }\end{array}$ & $\begin{array}{l}\text { Occasional concern with credibility } \\
\text { (relationships, expertise) }\end{array}$ & Multiple and competing sources of CA & 15 \\
\hline 24. TransCo & $\begin{array}{l}\text { Centralised unit - operational } \\
\text { efficiency. }\end{array}$ & $\begin{array}{l}\text { Occasional concern with credibility } \\
\text { (relationships) unit disbanded. }\end{array}$ & $\begin{array}{l}\text { Multiple but non-competing sources of } \\
\text { CA. }\end{array}$ & 2 \\
\hline
\end{tabular}


TABLE 2 Competition and credibility in change agency

Challenge to change agency development

Occupational congestion and diverse roles

Establishing credibility through:

Relationships

Expertise

Identifying added-value
Key features and experiences of change agents

- Change agents with variety of professional backgrounds

- Alternative internal providers of change expertise

- Range of structures/roles for change agency

- Senior management sponsorship and client status

- Extending / diversifying client base

- Relative expertise in change agency

- Professional / occupational identities

- Desire to undertake strategic work

- Diversification of products and services 